\title{
Green synthesis of silver nanoparticles (AgNPs) using of Laurus nobilis L. leaf extracts and evaluating its antiarthritic activity by in vitro protein denaturation and membrane stabilization assays
}

Abubucker Peer Mohideen

Department of Basic Medical Sciences, College of Medicine, Prince Sattam bin Abdulaziz University, Al-Kharj, 11942, Saudi Arabia.

\begin{tabular}{l} 
Article Info \\
\hline Article history \\
Received 1 November 2021 \\
Revised 16 December 2021 \\
Accepted 17 December 2021 \\
Published Online 30 December 2021
\end{tabular}

\section{Keywords}

Autoimmune diseases

Antiarthritic activity

Silver nanoparticles

Green synthesis

Laurusnobilis

\begin{abstract}
Arthritis, a systemic autoimmune disease that involves synovial growth and cartilage breakdown produces persistent inflammation of connective tissue, particularly in the joints. Arthritis is more common in persons over 65 , but it can strike anyone at any age (including children). Antiarthritic medicines can help with arthritis treatment, but they can also cause dizziness, drowsiness, headaches, swollen or painful gums, hair loss, decreased appetite, mouth sores, rash, diarrhoea and several adverse side effects. Thus, there is a need for the development of novel antiarthritic drugs. Therefore, the present study focuses on the green synthesis of silver nanoparticles using leaf extracts of Laurus nobilis L. and evaluating its antiarthritic activity. The silver nanoparticles were synthesized and characterized using UV-Vis spectroscopy and dynamic light scattering. The in vitro antiarthritic activity of the green synthesized AgNPs was determined using protein denaturation and RBC membrane stabilization methods. The UV-Vis spectrum showed the nanoparticle peak at $396 \mathrm{~nm}$, and the average size of the nanoparticle was found to be $78.1 \mathrm{~nm}$. Five concentrations $(50 \mu \mathrm{g}, 100 \mu \mathrm{g}, 250 \mu \mathrm{g}, 500 \mu \mathrm{g}$ and $1000 \mu \mathrm{g})$ of AgNPs were used to compare with the standard drug (aspirin). AgNPs showed a significant inhibition percentage compared with the standard drug. An increase in concentration increases the inhibition percentage. Maximum inhibition of protein denaturation and membrane stabilization of AgNPs was observed to be $53.47 \pm 0.33 \%$ and $62.43 \pm 0.25 \%$ at $1000 \mu \mathrm{g}$ concentration. Therefore, AgNPs synthesized from L. nobilis can be used for the development of novel antiarthritic drugs.
\end{abstract}

\section{Introduction}

Autoimmune illnesses are pathological conditions characterised by autoantibodies and T-cell responses to self-molecules due to immune system reactivity. The immune system destroys or disrupts the body's own tissues as a result of a complex combination of hereditary and environmental factors. Both of these factors influence autoimmunity susceptibility on three levels: the immune system's overall reactivity, the individual antigen and its presentation, and the target tissue. Most autoimmune diseases are thought to be polygenic, involving more than one gene. For clinicians, autoimmune diseases appear either systemic (e.g., systemic lupus erythema-tosus) or organ-specific (e.g., type 1 diabetes mellitus). This classification, although clinically useful, does not necessarily correspond to a difference in causation (Van Delft and Huizinga, 2020).

Arthritis is a disease that causes one or more joints to swell and become painful. Joint pain and stiffness are the most common symptoms of arthritis, which normally worsen with age. Rheumatoid arthritis and osteoarthritis are the two most frequent kinds of arthritis. When the body's natural defence mechanism can not

Corresponding author: Dr. Abubucker Peer Mohideen Department of Basic Medical Sciences, College of Medicine, Prince Sattam bin Abdulaziz University, Al-Kharj, 11942, Saudi Arabia. E-mail: peermdnnn@gmail.com Tel.: ++966553201774

Copyright () 2021 Ukaaz Publications. All rights reserved. Email: ukaaz@yahoo.com; Website: www.ukaazpublications.com distinguish the difference between our own cells and foreign cells, the body assaults them by mistake. This is how arthritis, which is a type of autoimmune illness, works. The autoimmune mechanism of arthritis is characterised by the immune system's attack on joints, which results in inflammation (Pandey et al., 2018).

Arthritis is more common in age 65 and older, according to the Centre for Disease Control and Prevention (CDC), but it can affect people of all ages (even children). Almost two-thirds of arthritis patients are under 65 years old. In every age group, women (26 per cent) have more arthritis than males (19\%), affecting people of all races and ethnicities. Adults who are obese are also more likely to develop arthritis than those who are normal weight or underweight. According to the CDC, $7.1 \%$ of adults aged 18 to 44 have been diagnosed with arthritis by a doctor. Doctor-diagnosed arthritis is reported by $29.3 \%$ of adults aged 45 to 64 . Doctor-diagnosed arthritis is reported by $49.6 \%$ of people aged 65 and over (Prothero et al., 2018).

Antiarthritic medicines can help with arthritis treatment, but they can also cause dizziness, drowsiness, headaches, swollen or painful gums, hair loss, decreased appetite, mouth sores, rash, and diarrhoea in humans. The use of these drugs regularly can harm your stomach, kidneys, liver, and heart. Even early in therapy, over-the-counter medicines like ibuprofen (Advil, Motrin IB, and others) and naproxen sodium (Aleve) can induce stomach bleeding and kidney damage, as well as raise your risk of heart attack and stroke. As a result, the 
development of novel antiarthritic medications will assist in lessening the detrimental effects of arthritis (Wang et al., 2018).

Herbal drugs are promising for creating effective and novel pharmaceuticals because plants are a rich source of novel phytocompounds. India is projected to have around 47,500 plant species, accounting for more than $11.4 \%$ of the world's total plant species. Approximately, $28 \%$ of the plants found in India are indigenous to the country. These medicinal herbs have various biological activities, including antibacterial, antidiabetic, antimicrobial, antiulcer, analgesic, and antiamnesic capabilities, among others. Medicinal herbs are commonly utilised and thought to be safe and less expensive than chemically manufactured medications (Umamaheswari et al., 2021). Various plants like A. paniculata, T. chebula, Terminalia bellirica, O. turpethum, etc., and herbal preparations like Triphala (comprising fruits of $P$. emblica or $E$. officinalis, T. chebula and T. bellirica) are also known to have potential antiarthritic and anti-inflammatory activities along with other medicinal properties (Punit et al., 2019; Tamanna Malik et al., 2020; Manubotula D. Sahithya et al., 2021).

Nanoparticles are particulate dispersions or stable debris with a length between 10 and 100 nanometers. Nanoparticles have unique capabilities determined by their size, shape, and morphology, allowing them to interact with plants, animals, and bacteria. Silver nanoparticles were one of the metals with enormous biological applications (Mathur et al., 2018). Different plants and their extracts have been used for the green synthesis of metal nanoparticls of gold, silver and zinc and have shown wide activities as anti-inflammatory agents (Santwana Palai et al., 2021). Antimicrobial capabilities of silver nanoparticles (AgNPs) have been demonstrated against a wide spectrum of bacteria. AgNPs are environmentally beneficial due to their use in electronics, catalysis, medicines, and pharmaceuticals (Mathur et al., 2018).

Therefore, the present study concentrates on the green synthesis of silver nanoparticles using extracts of $L$ nobilis. The nanoparticles were characterized using UV-Vis spectroscopy and dynamic light scattering. Further, the green synthesized silver nanoparticles were subjected to in vitro antiarthritic analysis.

\section{Materials and Methods}

\subsection{Collection of plant and processing}

The dry leaves of L. nobilis were procured from a local shop at Tharamani, Chennai and stored at room temperature. The dried leaves were finely grounded to powders and stored in a sterile container for extraction. Figure 1 shows the leaves of $L$. nobilis used in the study.

2.2 Extraction and green synthesis of silver nanoparticles (Ahmed and Mustafa, 2020)

The powders of leaves ( $20 \mathrm{~g}$ ) were finely chopped into small pieces and $100 \mathrm{ml}$ of deionized water was added, stirred for $20 \mathrm{~min}$ at $60^{\circ} \mathrm{C}$. The leaf extract was cooled at room temperature after boiling and filtered, conferring $75 \mathrm{ml}$ of leaf broth which was stored at $4^{0} \mathrm{C} .0 .1$ $\mathrm{M}$ (1.69 $\mathrm{g}$ in $100 \mathrm{ml}$ distilled water) of $\mathrm{AgNO}_{3}(99.99 \%)$ was used in the green synthesis of AgNPs. $5 \mathrm{ml}$ of leaf extract was introduced to $45 \mathrm{ml}$ of $0.01 \mathrm{M} \mathrm{AgNO}_{3}$ aqueous solution and allowed at suitable conditions to react. After various time intervals, the colour change of the reaction mixture is noticed from colourless to brownish-black designates that the synthesis of AgNPs. The AgNPs precipitates were procured through the centrifugation process. The pellets were collected and dried using a hot air oven at $50^{\circ} \mathrm{C}$ for $1 \mathrm{~h}$. The dried powders were collected and stored in sterile tubes.

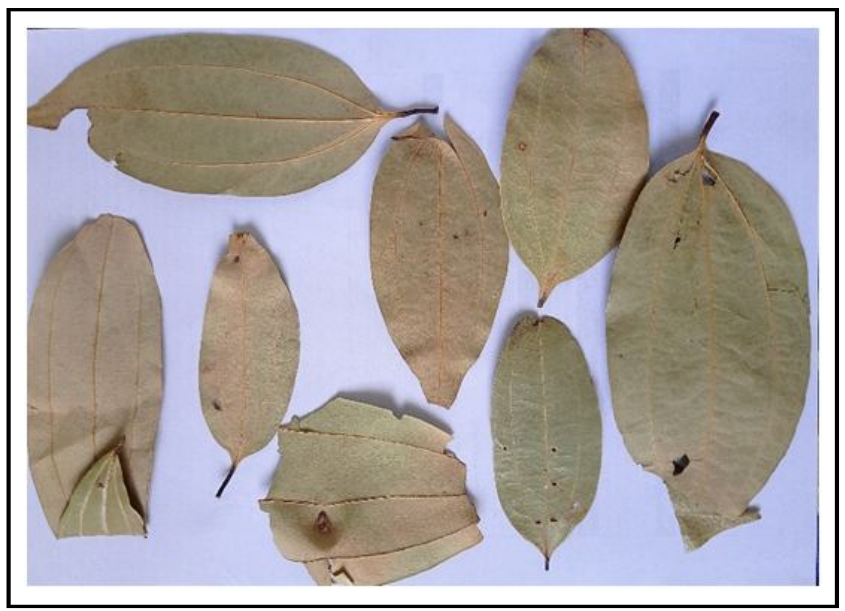

Figure 1: Laurusnobilis used in the study.

\subsection{Characterization of silver nanoparticles}

\subsubsection{UV-Vis spectroscopy analysis}

UV-visible spectroscopy (UV-Vis) is used to evaluate the unique optical properties of nanoparticles synthesized from certain metals like gold and silver, which strongly interacts with a specific wavelength $(\mathrm{nm})$ of light. UV-visible spectroscopy was performed to confirm the reduction of silver ions in the colloidal solution to silver oxide forms using Shimadzu -UV 1800. Double distilled water is used as reference and $1 \mathrm{ml}$ of the colloidal silver solution is poured in a quartz cuvette and subjected for wavelength scanning between 350 and $500 \mathrm{~nm}$.

\subsubsection{Dynamic light scattering}

Dynamic light scattering is used to identify the average size of the synthesized nanoparticles. Zeta analyser (Malvern Instruments) was used to quantify the size of the green synthesized nanoparticles (AgNPs).

\subsection{Antiarthritic activity (Mohamed et al., 2014; Saket et al., 2010)}

The antidenaturation study for analysing antiarthritic activity was carried out by utilising bovine serum albumin (BSA). When BSA is heated, antigens which are realted to to type-III hypersensitivity reactions are released, and are linked to disorders like rheumatoid arthritis.

\subsubsection{Inhibition of protein denaturation (Pavithra et al., 2015)}

The method was implemented from the previous article published by Pavithra et al. (2015) with slight alterations. The reaction mixture consisted of the $100 \mu \mathrm{l}$ of AgNPs (final concentration 50, 100, 250, $500,1000 \mu \mathrm{g} / \mathrm{ml}$ ) and $100 \mu \mathrm{l}$ of $5 \%$ aqueous solution of bovine serum albumin (BSA). The sample was incubated at $37^{\circ} \mathrm{C}$ for $20 \mathrm{~min}$, and the temperature was increased up to $70^{\circ} \mathrm{C}$ in a hot water bath for $10 \mathrm{~min}$. The tap water is used to cool the mixture for $10 \mathrm{~min}$ after which turbidity and absorbance were calculated at $660 \mathrm{~nm}$. The blank comprised of the distilled water. The findings were compaired to those of the commonly used medication aspirin. 


\section{Formula used}

Percentage inhibition $=$ Abs control - Abs sample $/$ Abs control $\mathrm{x} 100$

\subsubsection{Effect on membrane stabilization (Vallabh et al., 2009)}

The technique used was from a procedure adopted by Vallabh Deshpande and his team with some variations. Blood sample from healthy human volunteers who did not consume NSAID for two weeks before this experiment was obtained. The reaction mixtures $4.5 \mathrm{ml}$ consists of $2 \mathrm{ml}$ hypotonic saline $(0.25 \% \mathrm{NaCl})+1 \mathrm{ml} 0.15$ $\mathrm{M}$ phosphate buffer $(\mathrm{pH} 7.4)+1 \mathrm{ml}$ test sample $(50-1000 \mu \mathrm{g} / \mathrm{ml})$ in normal saline $+0.5 \mathrm{ml}$ of $10 \% \mathrm{HRBC}$ in normal saline. For $30 \mathrm{~min}$, the mixture was incubated at $56^{\circ} \mathrm{C}$. All the test tubes were cooled for 20 min under running tap water. After that, reaction mixture was centrifuged at $3000 \mathrm{rpm}$ for $10 \mathrm{~min}$, and the absorbance of the supernatant was calculated at $560 \mathrm{~nm}$.

\section{Formula used}

Percentage inhibition $=$ Abs control - Abs sample $/$ Abs control $\mathrm{x} 100$

\section{Results}

\subsection{Green synthesis of silver nanoparticles}

Green synthesis involves the usage of plant extracts as the reducing agents. The colour change from colourless to black colour on the addition of plant extract indicates the formation of silver nanoparticles. Figure 2 shows the formation of silver nanoparticles on the addition of plant extracts. The nanoparticles were centrifuged, collected and dried for further analysis.

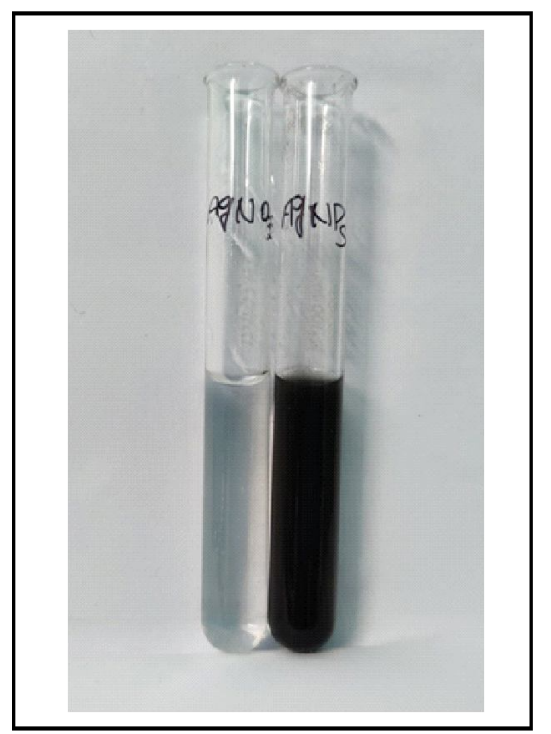

Figure 2: Green synthesis of silver nanoparticles.

\subsection{Characterization of silver nanoparticles}

Green synthesized silver nanoparticles were characterized using UVvis spectroscopy and dynamic light scattering. UV-vis spectroscopy is the basic instrumentation to confirm the successful synthesis of nanoparticles. The UV-vis spectrum of green synthesized silver nanoparticles showed peak at $396 \mathrm{~nm}$. The obtained peak is in the range of the silver nanoparticles. This confirms the effective synthesis of silver nanoparticles. Figure 3 shows the UV-vis spectrum of the green synthesized silver nanoparticles.

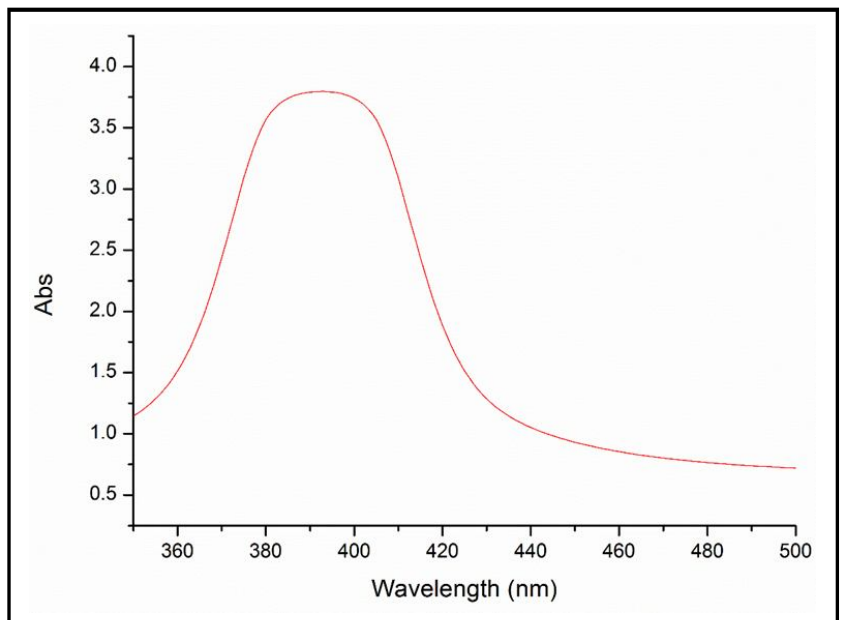

Figure 3: UV-Vis spectrum of the green synthesized AgNPs.

Dynamic light scattering is used to evaluate the average size of the nanoparticles. From the analysis, the average size of the green synthesized nanoparticles was observed to be $78.1 \mathrm{~nm}$. The distribution graph based on the intensity is shown in Figure 4.

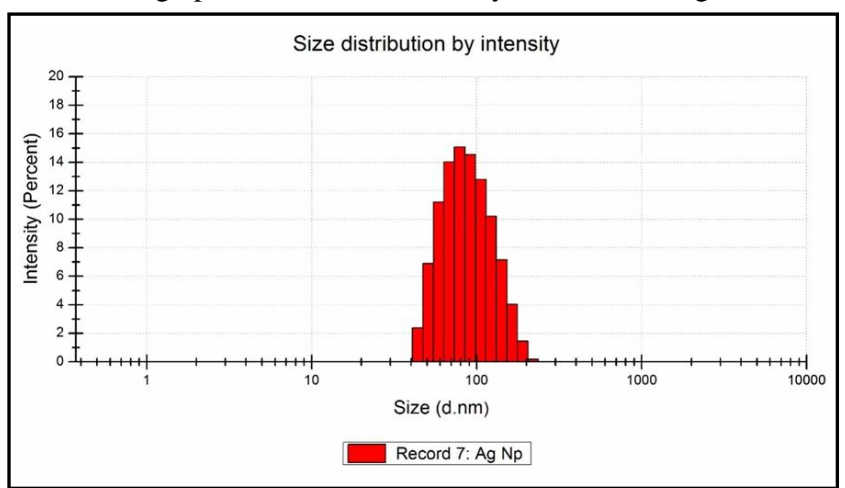

Figure 4: Particle size analysis of the green synthesized AgNPs.

3.3 Inhibition of protein denaturation

About five concentrations of the green synthesized silver nanoparticles were used for the inhibition of protein denaturation assay. $50 \mu \mathrm{g}$ of AgNPs showed $11.71 \pm 0.61 \%, 19.22 \pm 0.18 \%$ for $100 \mu \mathrm{g}, 33.41 \pm$ $0.52 \%$ for $250 \mu \mathrm{g}, 44.52 \pm 0.63 \%$ for $500 \mu \mathrm{g}$ and $53.47 \pm 0.33 \%$ for $1000 \mu \mathrm{g}$. Similarly, $50 \mu \mathrm{g}, 100 \mu \mathrm{g}, 250 \mu \mathrm{g}, 500 \mu \mathrm{g}$ and $1000 \mu \mathrm{g}$ of the standard drug (aspirin) showed $15.37 \pm 2.54 \%, 31.9 \pm 0.96 \%, 42.19$ $\pm 1.38 \%, 68.24 \pm 0.88 \%$ and $81.49 \pm 1.05 \%$ of inhibition. Figure 5 shows the graphical representation of protein denaturation inhibition of silver nanoparticles on compared with standard drugs.

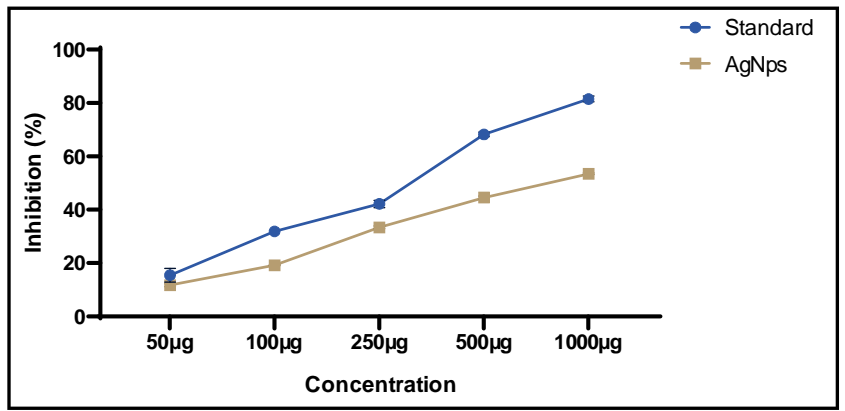

Figure 5: Inhibition of protein denaturation analysis. 


\subsection{Membrane stabilization assay}

RBC's from volunteers who did not consume NSAID for past two weeks were collected and utilized in this study. $50 \mu \mathrm{g}, 100 \mu \mathrm{g}, 250$ $\mu \mathrm{g}, 500 \mu \mathrm{g}$ and $1000 \mu \mathrm{g}$ of the standard drug (aspirin) showed 17.42 $\pm 0.19 \%, 22.87 \pm 0.34 \%, 37.61 \pm 0.26 \%, 45.22 \pm 0.47 \%$ and 62.43 $\pm 0.25 \%$ of inhibition of haemolysis. At the same time, standard drug (aspirin) showed $22.35 \pm 1.26 \%, 35.73 \pm 0.99 \%, 47.07 \pm 2.53 \%$, $64.65 \pm 1.28 \%$ and $86.49 \pm 0.23 \%$ inhibition of hemolysisfor $50 \mu \mathrm{g}$, $100 \mu \mathrm{g}, 250 \mu \mathrm{g}, 500 \mu \mathrm{g}$ and $1000 \mu \mathrm{g}$ concentrations. Figure 6 shows the inhibition of AgNPs by RBC membrane stabilization method.

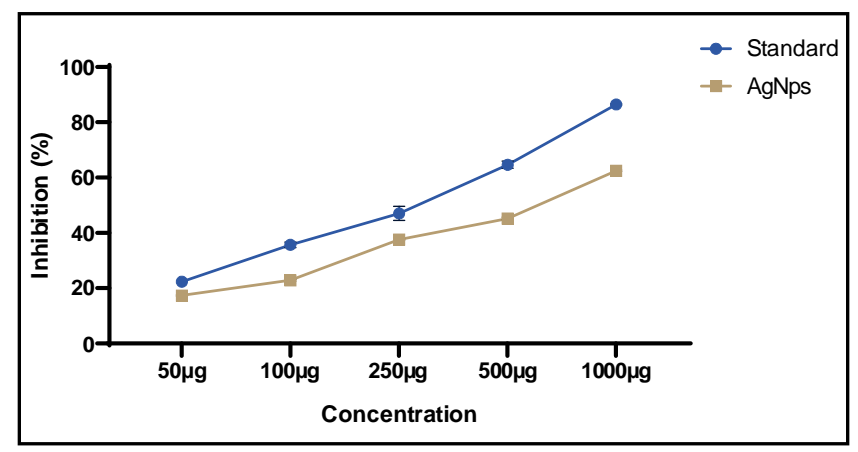

Figure 6: Membrane stabilization potential of AgNPs.

\section{Discussion}

Arthritis is a systemic autoimmune disease that involves synovial growth and cartilage breakdown and produces persistent inflammation of connective tissue, particularly in the joints. The first joint tissue to be affected is a synovial membrane which lays the joint cavity (Kim et al., 2009). As there are several antiarthritic drugs which cause adverse side effects, the present study concentrates on the green synthesis of silver nanoparticles using extracts of $L$. nobilis.

Bay leaf, also known as laurel leaf, is the leaf of the sweet bay tree (L. nobilis), an evergreen of the Lauraceae family, native to Mediterranean regions. They contain about 2\% essential oil, with cineole being the most important component. L. nobilis, a flowering plant in the Lauraceae family, is an aromatic evergreen tree or big shrub with green, glabrous smooth leaves. It comes from the Mediterranean region and is used to season food as a bay leaf. It grows in full sun to light shade and tolerates a variety of well-drained soil types. It is a slow-growing plant that has been utilised as a hedge or topiary. In places colder than zone $8 \mathrm{~b}$, it must be carried indoors throughout the winter to avoid frost damage. L. nobilisis an important industrial plant that is used in foods, pharmaceuticals, and cosmetics. Bay is utilised in the food sector as a food preservative because of its antibacterial and insecticidal properties. It has traditionally been used to treat rheumatism and dermatitis, as well as gastrointestinal issues such as epigastric bloating, poor digestion, eructation, and flatulence. Turkish folk medicine uses the aqueous extract as an antihemorrhoidal, antirheumatic, diuretic, antidote for snakebites, and stomachache treatment (Tharun et al., 2017; Usmani et al., 2021).

The silver nanoparticles were synthesized using the extracts of L. nobilis and characterized using UV-vis spectroscopy and dynamic light scattering. The UV-vis spectrum showed the nanoparticle peak at $396 \mathrm{~nm}$, and the average size of the nanoparticle was found to be $78.1 \mathrm{~nm}$. The obtained size is the range of the standard nanoparticle $(<100 \mathrm{~nm})$. The characterization analysis showed the effective synthesis of silver nanoparticles from leaf extracts of L. nobilis. The in vitro antiarthritic activity of the green synthesized AgNPs was determined using protein denaturation and RBC membrane stabilization methods. The inhibition of protein denaturation and inhibition of hypotonicity induced membrane stabilization was considered as a measure of antiarthritic activity. Five concentrations $(50 \mu \mathrm{g}, 100 \mu \mathrm{g}, 250 \mu \mathrm{g}, 500 \mu \mathrm{g}$ and $1000 \mu \mathrm{g}$ ) of AgNPs were used in the study to compare with the standard drug (aspirin). AgNPs showed significant inhibition on both the assay on compared with the standard. An increase in concentration increases the inhibition percentage. This shows that the antiarthritic activity of the AgNPs was concentration dependent.

When live tissue is harmed, protein denaturation occurs, which leads to the inflammation process. Hydrogen, disulphide bonds are formed as a result of the electrostatic disruption, resulting in protein denaturation. The compounds that prevent these alterations tend to possess antiarthritic properties. The stability of the RBC membrane was identical to that of the lysosomal membrane, which regulates the inflammatory process. The inflammatory response of the lysosomal membrane was significant because it aids the inhibition process by preventing the release of activated neutrophil lysosomal components. Thus, the green synthesized AgNPs possibly inhibit the release of lysosomal neutrophil contents at the inflammatory site (Joshi et al., 2021).

\section{Conclusion}

Green synthesis of silver nanoparticles was carried out using the leaf extracts of $L$. nobilis. The silver nanoparticles were synthesized and characterized using UV-vis spectroscopy and dynamic light scattering. The in vitro antiarthritic activity of the green synthesized AgNPs was determined using protein denaturation and RBC membrane stabilization methods. AgNPs showed a significant inhibition percentage on compared with the standard drug. Increase in concentration increases the percentage of inhibition. Therefore, AgNPs synthesized from $L$. nobilis can be used for the treatment of arthritis. Further, the green synthesized silver nanoparticles can be subjected to in vitro enzymological studies and in vivo animal studies for development of novel antiarthritic drugs.

\section{Acknowledgements}

The author is thankful to the Deanship of Scientific Research, Prince Sattam bin Abdulaziz University, Al-Kharj, Saudi Arabia, for its support in conducting the research and publishing this report.

\section{Conflict of interest}

The author declares no conflicts of interest relevant to this article.

\section{References}

Ahmed, R.H. and Mustafa, D.E.(2020). Green synthesis of silver nanoparticles mediated by traditionally used medicinal plants in Sudan. Int. Nano Lett. 10:1-14. https://doi.org/10.1007/s40089-019-00291-9

Joshi, D.G.: Jat, D.R.K. and Patil, D.S.B.(2021). In vitro protein denaturation and membrane stabilizing antiarthritic activity of aqueous extracts of bark of Ficus benghalensis L. against methotrexate. Pharma Innov, 10:689-692. https://doi.org/10.22271/tpi.2021.v10.i4j. 6038 .

Kim, P.S., Klausmeier, T.L. and Orr, D.P. (2009). Reactive arthritis: A teview. J. Adolesc. Heal. https://doi.org/10.1016/j.jadohealth.2008.12.007. 
Manubotula Durga Sahithya.; Mote Srinath.; Bukhya Chaitanya Kumar and Charu Chandra Giri (2021). Molecular in silico docking interventions in various SARS-CoV-2 receptor targets involving bioactive herbal compounds of Andrographis paniculata (Burm. f.) Nees against COVID-19. Ann. Phytomed., Volume10, Special Issue1 (COVID19):S22-S39. http://dx.doi.org/10.21276/ap.covid19.2021.10.1.4

Mathur, P.; Jha, S.; Ramteke, S. and Jain, N.K. (2018). Pharmaceutical aspects of silver nanoparticles. Artif. Cells, Nanomedicine Biotechnol., https://doi.org/10.1080/21691401.2017.1414825.

Mohamed, M. and Shabi Subashini Utharpathy (2014). Chellappan David Raj, Gayathri Krishnamoorthy. Analgesic and Antiarthritic effects of Enicostemma hittorale Blume, Advances in Bioscience and Biotechnology, 5:1018-1024.

Pandey, P.; Tiwari, S. and Priyanka Pandey, C. (2018). Therapeutic potential of Indian plants for the treatment of rheumatoid arthritis. $37 \mathrm{~J}$. Pharmacogn. Phytochem, 7:37-41.

Pavithra, T.K.; Smitha, K.P.; Kulashekar, K.S. and Ashok Kumar B.S. (2014). Evalation of in vitro Antiarthritic activity of Vitex negundo against the Denaturation of Protein, Int. J. Curr. Micribiol, App. Sci., 9:87-90.

Prothero, L.; Barley, E.; Galloway, J.; Georgopoulou, S. and Sturt, J. (2018). The evidence base for psychological interventions for rheumatoid arthritis: A systematic review of reviews. Int. J. Nurs. Stud. https:/ /doi.org/10.1016/j.ijnurstu.2018.03.008.

Punit, R. Bhatt.; Kajal, B. Pandya.; Urvesh D. Patel.; Chirag, M. Modi.; Harshad B. Patel and Bhavesh B. Javia (2019). Antidiabetic, antioxidant and antiinflammatory activity of medicinal plants collected from nearby area of Junagadh, Gujarat. Ann. Phytomed., 8(2):75-84
Saket, S.S.; Juvekar, A.R. and Gambhire, M.N. (2010). In vitro antioxidant and anti-inflammatory activity of methanol extract of Oxalis corniculate L. Int. J. Pharm Sci. 2:146-155.

Santwana Palai, Ritun Patra and Manaswini Dehuri (2021). Phytonanoparticles and COVID-19. Ann. Phytomed., Volume10, Special Issue1 (COVID19): S222-S230. http://dx.doi.org/10.21276/ap.covid19. 2021.10. 1.20 .

Tamanna Malik, Madan, V. K. and Ram Prakash (2020). Herbs that heal: Floristic boon to the natural healthcare system. Ann. Phytomed., 9(2):614. http://dx.doi.org/10.21276/ap.2020.9.2.2.

Tharun, G; Ramana, G.; Sandhya, R. and Shravani, M. (2017). Phytochemical and pharmacological review on Laurus nobilis. J. Pharm. Res., $11: 249-256$

Umamaheswari, D.; Muthuraja, R.; Kumar, M. and Venkateswarlu, B.S. (2021). Standardization of herbal drugs: A overview. Int. J. Pharm. Sci. Rev. Res., 68. https://doi.org/10.47583/ijpsrr.2021.v68i01.033.

Usmani, Q.I.; Ahmad, A. and Jamaldeen, F.N. (2021). L. nobilis L. (Habb-ulGhar) A review on phytochemistry, pharmacology and ethnomedicinal uses. J. Drug Deliv. Ther., 11:136-144. https://doi.org/ 10.22270/jddt.v11i5.5021

Vallabh Deshpande, Varsha Jadhav, M and KadamV. J. (2009). In vitro antiarthritic activity of Abutilam indicum (Linn,), J. Pharm. Res., 2(4):644-645.

Van Delft, M.A.M. and Huizinga, T.W.J. (2020). An overview of autoantibodies in rheumatoid arthritis. J. Autoimmun. https://doi.org/10.1016/ j.jaut.2019.102392

Wang, W.; Zhou, H. and Liu, L. (2018). Side effects of methotrexate therapy for rheumatoid arthritis: A systematic review. Eur. J. Med. Chem. https://doi.org/10.1016/j.ejmech.2018.09.027. 